\title{
INFLUÊNCIA DA CAPACIDADE DE ABSORÇÃO INDIVIDUAL NA INTENÇÃO EMPREENDEDORA DOS DISCENTES QUE PARTICIPARAM DO FESTIVAL DE ARTES EMPREENDEDORAS
}

Maria Andréa Rocha Escobar ${ }^{1}$

Lucas Andrade Santos ${ }^{1}$

${ }^{1}$ Campus Professor Alberto Carvalho (Itabaiana) / Universidade Federal de Sergipe 


\section{INFLUÊNCIA DA CAPACIDADE DE ABSORÇÃO INDIVIDUAL NA INTENÇÃO EMPREENDEDORA DOS DISCENTES QUE PARTICIPARAM DO FESTIVAL DE ARTES EMPREENDEDORAS}

\section{RESUMO}

Este artigo tem por objetivo analisar a influência da Capacidade de Absorção Individual na Intenção Empreendedora dos discentes que participaram do Festival de Artes Empreendedoras. Para tanto, utilizou-se de uma abordagem quantitativa e de natureza descritiva e correlacional. Os dados foram obtidos de fontes primárias por meio de survey com questionário. Para a avaliação da relação entre os construtos, foram utilizadas a análise multivariada. A amostra da pesquisa foi composta por 80 discentes dos cursos de bacharelado do Campus Professor Alberto Carvalho da Universidade Federal de Sergipe, Campus Itabaiana. Os resultados evidenciaram que a capacidade absortiva individual tem influência positiva na intenção empreendedora, mostraram também que a intenção empreendedora é refletida pelas atitudes relativas ao comportamento, normas subjetivas e controle do comportamento percebido da Teoria do comportamento planejado da intenção empreendedora.

Palavras chaves: Capacidade de Absorção Individual; Intenção Empreendedora; Festival de Artes Empreendedoras. Discentes.

\section{INTRODUÇÃO}

As relações entre as empresas e os ambientes nos quais estão inseridas são consideradas desafiadoras e relevantes à estratégia organizacional. Os indivíduos também se utilizam dos ambientes externo e interno para a troca de conhecimento para proporcionar as empresas um melhor conhecimento do mercado em que atuam, para assim ganhar vantagem competitiva e sustentabilidade.

$\mathrm{Na}$ literatura existem diferentes definições para a capacidade de absorção e intenção empreendedora. Assim, em alguns estudos os constructos são analisados de forma ampla, tanto em nível coletivo como individual. $\mathrm{O}$ ambiente é definido como a totalidade de fatores sociais que são levados em consideração no comportamento decisório dos indivíduos da organização, dessa maneira contribuem para o desenvolvimento de ações voltadas à estratégia da empresa.

Nos últimos anos, houve um crescimento no número de pesquisas sobre a habilidade que os indivíduos e as empresas têm de absorver o conhecimento do ambiente externo, como também estudos relacionados à intenção empreendedora. Contudo, em torno desses conceitos existe diferenças, o que pode ser atrelado ao seu estado relativamente recente de desenvolvimento, pois apenas se passaram pouco menos de três décadas desde a publicação da primeira definição.

Nos estudos sobre empreendedorismo, são apresentados elementos como propensão para empreender, a oportunidade dos indivíduos para atuar, o ambiente das organizações, 
influência da sociedade na intenção empreendedora. Este processo se agrega ao da capacidade de absorção individual, pois estes dependem diretamente do indivíduo.

A partir desse contexto, as organizações percebem a capacidade de absorção e a intenção empreendedora como fatores necessários e responsáveis pelo desenvolvimento de novos conhecimentos e tecnologias nas organizações. Por serem temas diretamente ligados à estratégia das empresas e que podem contribuir para melhoria dos processos organizacionais, se faz necessário estudos voltados ao entendimento da relação entre os constructos. A fim de estudar e apresentar pontos importantes sobre essa temática, foi definido o seguinte problema de pesquisa: como a capacidade de absorção individual influencia na intenção empreendedora dos discentes que participaram do Festival de Artes Empreendedoras?

\section{REFERENCIAL TEÓRICO}

\subsection{Capacidade de Absorção Individual (CAI)}

Os indivíduos são os principais responsáveis pela geração e atualização de conhecimento nas organizações, além disso a capacidade absortiva da organização está diretamente ligada às estruturas individuais (VERGA-JURADO, GUTIERREZ-GRACIA, FERNANDEZ-DE-LUCIO, 2008). Os autores ainda destacam que para compreender melhor os processos de conhecimento dentro da empresa, é importante que se analise a capacidade de absorção em nível individual, assim possibilita entender a troca de conhecimento entre o ambiente externo e interno (LACERDA, 2017).

Dessa forma, a capacidade absortiva em nível organizacional depende principalmente das habilidades e conhecimentos individuais das pessoas. Portanto, é necessário que a organização invista nos seus recursos humanos para que reforcem, complementem e transformem o conhecimento que já possuem, desse modo possibilita o desenvolvimento de sua capacidade absortiva individual (LANE; LUBATKIN, 1998). Funcionários motivados em alcançar os objetivos organizacionais, consequentemente, permitem que a empresa aumente sua capacidade absortiva (COHEN; LEVINTHAL, 1990; KIM, 1998).

É importante ressaltar que a capacidade de uma organização absorver conhecimento externo está diretamente relacionada a fatores das habilidades e competências dos indivíduos, como por exemplo, suas ações voltadas ao planejamento e desenvolvimento de novos produtos e serviços. Essas ações são responsáveis e interferem de forma efetiva nas estratégias da empresa e na sua capacidade de receber conhecimento externo (ANDRADE, 2017).

No entanto, o processo de adaptação do conhecimento adquirido às rotinas organizacionais apresenta grandes riscos, pois o conhecimento externo pode conter particularidades incompatíveis com o conhecimento já existente (LANE; LUBATKIN, 1998). Por isso, a empresa precisa investir em membros preparados para as necessidades, rotinas, e recursos para evitar ou reduzir as possíveis incompatibilidades (COHEN; LEVINTHAL, 1990; WANG et al 2014).

Lacerda (2017) ressalta que a capacidade de absorção da empresa sofrerá constantemente influência do conhecimento dos indivíduos. Desse modo, é preciso equilíbrio entre essas capacidades para que as dimensões possam ser utilizadas interligadas entre si e entre a organização e seus indivíduos. Portanto, quanto melhor for o equilíbrio, melhor será a exploração e maximização da capacidade de absorção individual e aumento do desempenho organizacional. 
Além disso, as pessoas também possuem e desenvolvem habilidades e características voltadas para a intenção empreendedora, pois esta é relacionada ao comportamento e é considerado como um estado de espírito em que o indivíduo se dedica para uma determinada situação a fim de alcançar seus objetivos. Sob essa perspectiva, pode-se considerar a intenção empreendedora como um fato complexo, versátil que envolve o indivíduo, a empresa e está ligado à capacidade de absorção individual (GIMENEZ, FERREIRA e RAMOS, 2008).

Os autores Wang et al (2014) em sua pesquisa realizada com 205 funcionários que utilizavam sistemas de inteligência na China, deram uma maior importância à capacidade absortiva individual. A partir desse estudo, os autores destacam que são os indivíduos os responsáveis pela aquisição, assimilação, transformação e exploração dos conhecimentos, dessa maneira, eles contribuíram para o desenvolvimento do tema e reforçaram os conceitos sobre o constructo da capacidade de absorção individual e também sobre o comportamento dos indivíduos (ANDRADE, 2017; LACERDA, 2017).

\section{Quadro 1 - Itens do Constructo Capacidade de Absorção Individual}

\begin{tabular}{l} 
Aquisição \\
\hline $\begin{array}{l}\text { AQ1 - Eu regularmente recolho informação através de meios informais (por exemplo: conversas informais, } \\
\text { grupos no whatsApp e redes sociais). }\end{array}$ \\
\hline $\begin{array}{l}\text { AQ2 - Eu regularmente observo o ambiente externo (mercado) para obter novas informações, conhecimentos } \\
\text { ou tecnologias. }\end{array}$ \\
\hline $\begin{array}{l}\text { AQ3 - Eu regularmente me aproximo de pessoas para adquirir novos conhecimentos, com o objetivo de } \\
\text { aprimoramento pessoal e profissional. }\end{array}$ \\
AQ4 - Eu regularmente pesquiso várias fontes de informações relevantes às atividades no meu dia a dia. \\
\hline $\begin{array}{l}\text { AQ5 - Eu me mantenho constantemente atualizado com as últimas tecnologias ou conhecimentos relacionados } \\
\text { a minha vida pessoal e profissional. }\end{array}$
\end{tabular}

a minha vida pessoal e profissional.

AS1 - Sou rápido em reconhecer e compreender a utilidade de novos conhecimentos para meu dia a dia.

AS2 - Eu compreendo rapidamente novas oportunidades para atender as necessidades da minha vida pessoal e profissional.

AS3 - Eu sei reconhecer e interpretar as mudanças em nosso mercado (por exemplo, concorrência, cliente e demanda).

AS4 - Sou capaz de analisar e interpretar o impacto das novas demandas na minha vida pessoal e profissional.

AS5 - Eu frequentemente me encontro com colegas para trocar e analisar novos conhecimentos ou desenvolvimentos tecnológicos.

\section{Transformação}

TR1 - Na minha área de atuação é comum eu armazenar o conhecimento recém adquirido para usar no futuro.

TR2 -Eu tenho a capacidade de conectar com sucesso o meu conhecimento com novos conhecimentos ou novas ideias.

TR3 - Eu comumente utilizo novos conhecimentos para gerar novas ideias para o meu dia a dia.

TR4 - Eu considero regularmente as consequências das mudanças nas exigências do mercado.

\section{Aplicação}

AP1 - Eu regularmente reconsidero meus processos de trabalho atuais (ou práticas) para adaptá-los em conformidade com o novo conhecimento ou tecnologias.

AP2 - Eu tenho a capacidade de trabalhar de forma mais eficaz através da adoção de novos conhecimentos ou tecnologias.

AP3 - No meu dia a dia, eu utilizo regularmente novos conhecimentos ou novas tecnologias para desenvolver novas formas de fazer as coisas.

AP4 - No meu dia a dia, eu sou eficiente em transformar novos conhecimentos em melhores processos de trabalho.

AP5 - Eu regularmente considero a melhor forma de aplicar novos conhecimentos ou tecnologias no meu dia a dia.

Fonte: Adaptado de Wang et al (2014).

DOI: $10.14211 /$ xi-egepe-118150 
O quadro acima apresenta os itens utilizados para mensurar a capacidade de absorção individual, o questionário foi adaptado a partir do modelo desenvolvido e validado por Wang et al (2014) em sua pesquisa. Os itens foram desenvolvidos tendo como base os conceitos e as dimensões apresentadas por Zahra e George (2002), elas permitem entender e mensurar o constructo estudado.

\subsection{Intenção Empreendedora (IE)}

A intenção empreendedora (IE) surge como o princípio do comportamento, sendo que quanto mais forte é a intenção de desenvolver um determinado comportamento, maior será a probabilidade da sua realização efetiva (AJZEN, 1991). Ou seja, antes mesmo de o empreendedor praticar suas ações, haverá uma intenção.

Alguns autores criaram modelos de intenção empreendedora, como: Modelo de Evento Empreendedor de Shapero e Sokol (1982); modelos derivados da Teoria do Comportamento Planejado de Ajzen (1991); e, o Modelo de Mensuração da Intenção Empreendedora de Linãn e Chen (2009). Sendo que, para os autores, esses são os principais modelos apresentados que tinham como objetivo dar maior destaque no contexto da intenção empreendedora.

Baseado nisso, será realizada uma breve revisão dos modelos aqui citados e posteriormente se deterá com mais detalhes ao modelo de Liñan e Chen (2009) por ser a base do modelo adotado nesta pesquisa. Shapero e Sokol (1982) propõem que quando o indivíduo escolhe empreender, tal fato surge de um fato ou mudança imediata no dia a dia do mesmo. Com isso, suas decisões traduzem-se dos elementos:

a) percepção da desejabilidade - percepções de conveniência, atratividade pessoal por empreender, englobando impactos pessoais e intrapessoais extras; b) Propensão para agir - o quanto o indivíduo está disposto a envolver-se em uma decisão, mostrando aspectos volitivos de intenções; e, c) Percepção de viabilidade - qual é o grau de sentimento do indivíduo em relação a sua capacidade de empreender.

Em contrapartida, o modelo de Ajzen (1991) propõe que todo o comportamento exige um processo de planejamento, ou seja, tenta explicar o comportamento humano levando em consideração as situações particulares de intencionalidade e contém três variáveis independentes, as quais estão ligadas a formação da intenção e, consequentemente, o comportamento (AJZEN, 1991).

O modelo é composto pelas dimensões da atitude pessoal (permite decidir o momento mais adequado para determinado comportamento), normas subjetivas (percepção do próprio indivíduo sobre a sociedade em que está inserido) e comportamento controlado (relaciona-se com o grau de percepção de controle individual) conforme apresentado na figura 2.

Figura 2 - Modelo Teoria do Comportamento Planejado de Ajzen (1991)

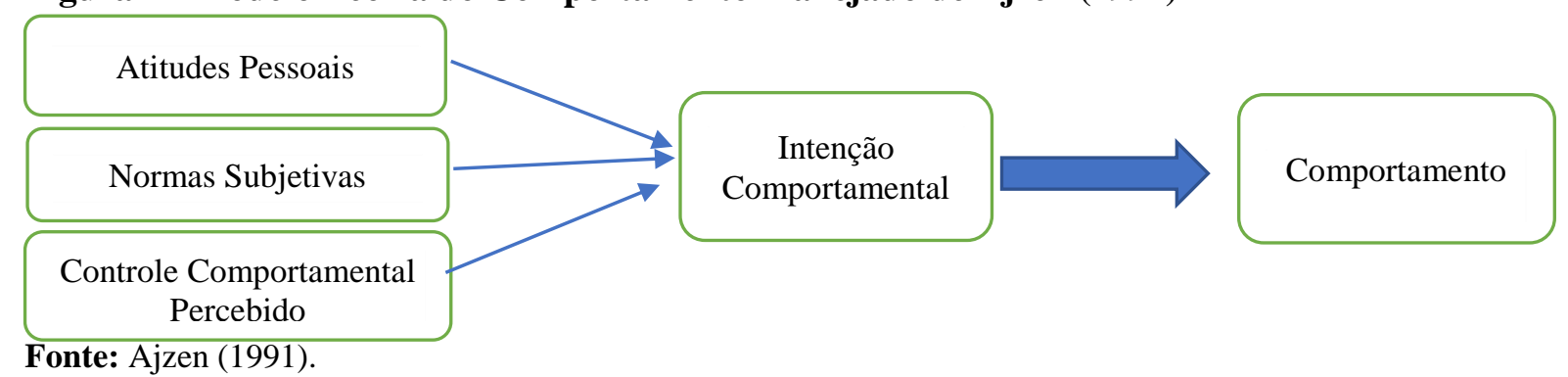


A partir do modelo proposto, Ajzen (1991) ressalta que as crenças normativas do indivíduo são influenciadas pelas normas subjetivas que, consequentemente acabam refletindo na intenção e no comportamento. Nesse sentido, as chamadas crenças de controle também possuem influência na intenção e comportamento, mas, é importante considerar que entre a intenção e o comportamento existe um controle de comportamento real (AJZEN, 1991).

De acordo com a Teoria do Comportamento Planejado (TCP) é possível prever a ação futura do indivíduo quando se tratar de empreender. A TCP surge da psicologia social como uma ampliação da teoria da ação racional que busca dar destaque a intenção do indivíduo na prática de um comportamento em específico (AJZEN, 1991). Um importante pesquisador da TCP é Liñán, que deu origem ao modelo de Chen e Liñán $(2006,2009)$ que também tem como base a TCP de Ajzen (1991).

A Teoria do Comportamento Planejado (TCP) destaca-se como um modelo fundamental na mensuração da intenção empreendedora, isso porque é ampla e consegue abordar o complexo comportamento do indivíduo bem como, os determinantes que são relevantes para este comportamento. Assim, para a TCP o mais importante é conseguir identificar o comportamento do indivíduo como algo responsável pela intenção (KOE, SA'ARI, MAJID, ISMAIL, 2012).

Percebendo a necessidade de suprir a falha a respeito da identificação do comportamento do indivíduo como algo responsável pela intenção, os autores Liñán e Chen (2009) criaram um instrumento que passou a permitir a mensuração da intenção empreendedora, o qual teve como base o modelo apresentado na figura 3.

Figura 3 - Modelo Intenção Empreendedora de Liñán e Chen (2009)

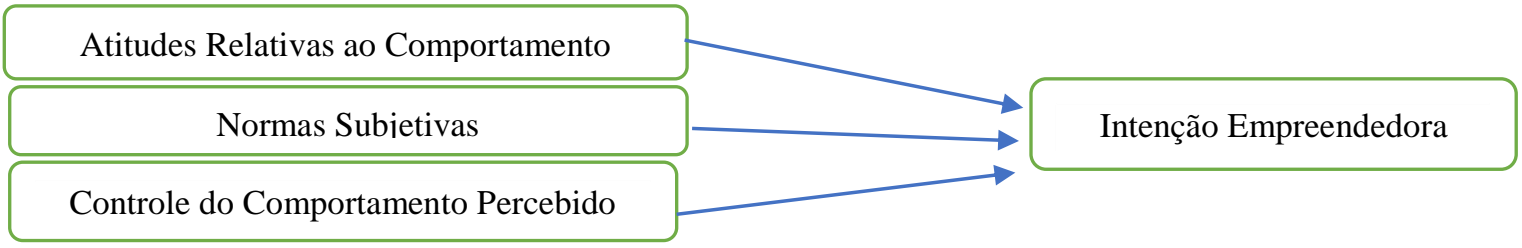

Fonte: Liñán e Chen (2009).

Conforme a figura acima, pode perceber as dimensões Atitudes Relativas ao Comportamento (ARC), Normas Subjetivas (NS) e o Controle Comportamental Percebido $\mathrm{CCP}$ ), influenciam o indivíduo a ser um empreendedor. Pode-se dizer também que a sociedade como um todo tem influência sobre o comportamento empreendedor (AJZEN, 1991).

A atitude relativa ao comportamento é considerada como o grau em que o indivíduo detém uma avaliação pessoal sobre ser um empreendedor. Enquanto as normas subjetivas se referem a pressão social percebida de possuir comportamento empreendedor. Outro fator que influencia a intenção empreendedora de um indivíduo é o controle comportamental percebido que surge com o intuito de mensurar a percepção do indivíduo quanto a facilidade ou dificuldade em que determinado comportamento seja praticado (LIÑÁN e CHEN, 2009).

Liñan e Chen (2009) desenvolveram um modelo nomeado de Entrepreneurial Intention Questionnaire (EIQ) que se fundamenta na TCP de Ajzen (1991), sendo um modelo que explica a intenção empreendedora. $\mathrm{O}$ quadro 2 apresenta os itens do constructo.

Quadro 2 - Itens do constructo intenção empreendedora

Intenção Empreendedora

IE1 - Eu tenho muito pouco interesse em começar a gerir uma empresa.

IE2 - Eu prefiro ser um gestor de uma empresa em vez de ser um funcionário em uma empresa.

IE3 - Estou pronto para fazer qualquer coisa para ser um gestor de empresa. 


\begin{tabular}{|l|}
\hline IE4 - Vou concentrar todos os meus esforços para iniciar e executar meu próprio negócio. \\
\hline Atitudes Relativas ao Comportamento \\
\hline ARC1 - Se eu tivesse oportunidade e recursos, gostaria de abrir uma empresa para mim. \\
\hline ARC2 - Ser um empreendedor implicaria grande satisfação para mim. \\
\hline ARC3 - Uma carreira como empresário é atraente para mim. \\
\hline Normas Subjetivas \\
\hline NS1 - Os seus parentes. \\
\hline NS2 - Os seus amigos mais próximos. \\
\hline NS3 - Os seus colegas. \\
\hline NS4 - Outras pessoas que são importantes para você. \\
\hline Controle Comportamental Percebido \\
\hline CCP1 - Iniciar a gestão de uma empresa e mantê-la funcionando seria fácil para mim. \\
\hline CCP2 - Estou preparado para iniciar um negócio viável. \\
\hline CCP3 - Eu posso controlar o processo de criação de uma nova empresa. \\
\hline CCP4 - Eu conheço os detalhes práticos necessários para criar uma nova empresa. \\
\hline CCP5 - Eu sei como desenvolver um projeto de criação de nova empresa. \\
\hline CCP6 - Se eu tentasse criar uma nova empresa, teria uma alta probabilidade de sucesso. \\
\hline
\end{tabular}

Fonte: Adaptado de Liñan e Chen (2009).

No quadro acima, destaca os itens utilizados para mensurar a intenção empreendedora. O modelo foi desenvolvido por Liñán e Chen (2009), tendo como base a TCP de Ajzen (1991). No Brasil, esse modelo foi validado por Souza (2015) em sua tese de doutorado, o autor usou o questionário para mensurar a intenção empreendedora em Universidades Federais do Mato Grosso do Sul. A partir das teorias e modelos apresentados, foi possível formular a hipótese do presente estudo.

H1: A capacidade de absorção individual tem influência positiva na intenção empreendedora.

\section{Figura 4 - Hipótese da pesquisa}

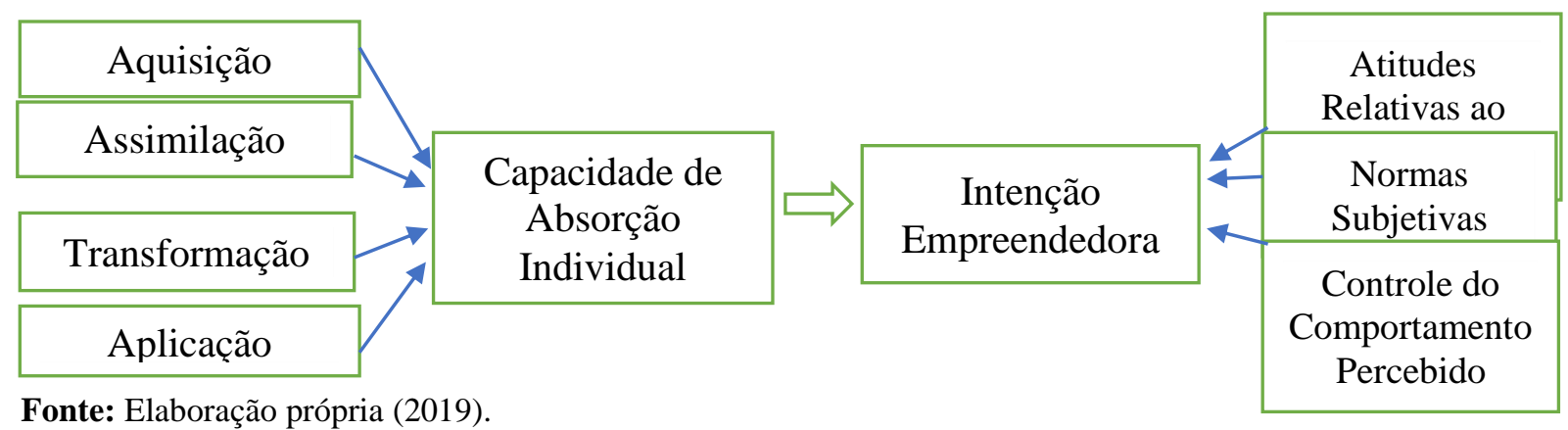

\section{METODOLOGIA}

Trata-se de uma pesquisa de abordagem quantitativa, pois para Cervo, Bervian, Da Silva, (2006) é a forma de explicar os fenômenos através da coleta de dados numéricos analisados por métodos estatísticos. O estudo também se caracteriza como de natureza descritiva e correlacional. Descritiva, pois como o próprio nome já diz, faz uma descrição das características de um fenômeno ou população e estabelece entre eles uma relação e, medem as características descritas em um problema de pesquisa, e tem por objetivo analisar e estudar as

DOI: $10.14211 /$ xi-egepe-118150 
características de determinado grupo. Correlacional, pois procura explorar as relações entre as variáveis (HAIR JR. et al., 2009). Na pesquisa em questão deseja-se descrever e explorar as relações entre os constructos capacidade de absorção individual e intenção empreendedora.

O Festival de Artes Empreendedoras é um evento realizado pelos discentes da disciplina de Iniciação Empresarial nos cursos de Administração, Ciências Contábeis e Sistemas de Informação da Universidade Federal de Sergipe, Campus Itabaiana. A partir disso a população da pesquisa foi definida como os discentes que participaram do evento nos anos de 2016 e 2017, totalizando 120 discentes. A amostra do estudo foi definida por acessibilidade e contém 80 respondentes.

Os dados foram obtidos de fontes primárias, por meio de survey com questionário. Os questionários foram aplicados aos respondentes de forma presencial e por e-mail. O instrumento de coleta contém 36 questões, sendo dividido em três blocos, especificados da seguinte forma: o primeiro bloco questiona sobre os aspectos sociais, o segundo bloco questiona sobre a capacidade absortiva individual, e o terceiro bloco aborda questões sobre a intenção empreendedora.

O constructo capacidade absortiva individual foi analisado a partir de um questionário adaptado do modelo de Wang et al (2014) que tem como base as dimensões definidas por Zahra e George (2002). O questionário aborda as seguintes medidas: Aquisição (AQ), Assimilação (AS), Transformação (TR) e Aplicação (AP). Os itens foram respondidos por meio de escala Likert de 5 pontos, onde 1 significa "discordo totalmente" e 5 significa "concordo totalmente".

A medidas para verificar a intenção empreendedora foram desenvolvidos por Liñán e Chen (2009). As medidas são: Intenção Empreendedora (IE), Atitudes em Relação ao Comportamento (ARC), Normas Subjetivas (NS) e Controle Comportamental Percebido (CCP). O questionário é composto por afirmativas respondidas em escala Likert de 5 pontos, onde 1 significa "discordo totalmente" e 5 significa "concordo totalmente".

Inicialmente os dados foram organizados em um banco de dados utilizando-se planilhas Excel®, que permitiu a realização da análise descritiva da amostra. Em seguida, os dados foram importados para o software SPSS ${ }^{\circledR}$ (Statistical Package for the Social Science) 23 que possibilitou a análise univariada dos dados. A partir disto, foi possível calcular a média, desvio padrão, assimetria e curtose para cada distribuição. O desvio padrão mede a uniformidade de um conjunto de dados, quanto mais próximo de zero mais homogêneo são os dados. Para os autores, assimetria é o quanto a curva de frequência se distancia da posição simétrica, já a curtose mede a dispersão ou a concentração de um conjunto de dados (FÁVERO et al., 2009). Ainda segundo os autores, se a assimetria se encontrar no intervalo de -2 até +2 e a curtose de -7 até +7 a distribuição é considerada normal.

Após a análise univariada dos dados, foi utilizada a Análise Fatorial Exploratória (AFE), análise correlacional e regressão múltipla linear. A opção por usar análise fatorial exploratória (AFE) na pesquisa aconteceu pela necessidade de analisar as inter-relações entre os itens das dimensões do constructo.

Nesse estudo a AFE foi aplicada para identificar a unidimensionalidade das dimensões da capacidade absortiva individual e da intenção empreendedora, e também para definir quantos itens foram utilizados. Para Hair Jr. et al. (2009) é possível utilizar a AFE quando a matriz de correlações atinge valores superiores à 0,30 nas correlações entre os itens, valores iguais ou maiores que 0,50 nas correlações entre o item e o total e comunalidade com valores acima de 0,40. Em seguida, foi realizada a medida de adequação da amostra utilizando o teste de Kayser - Meyer - Olkim (KMO), que permite valores acima de 0,50. Também foi realizado o teste de 
esfericidade de Bartlett, necessita que o valor $\mathrm{p}$ seja menor que 0,05. As cargas fatoriais dos itens que possuem valores menores que 0,60 foram excluídos. Após a aplicação da AFE, foi realizada a análise de regressão múltipla linear e correlação.

\section{RESULTADOS}

A amostra final desta pesquisa são 80 discentes que participaram do Festival de Artes Empreendedoras (FAE), desenvolvido na Universidade Federal de Sergipe, Campus Itabaiana.

A partir das análises foi possível observar que a maioria dos respondentes, $(63,70 \%)$ cursam Administração, esse fato é decorrente por conta de que o FAE é preferencialmente destinado aos alunos de administração. Dos respondentes, 13,80\% cursam Ciências Contábeis e 22,50\% são do curso de Sistemas de Informação.

Quanto ao gênero 55\% dos respondentes são do gênero masculino e $45 \%$ são do gênero feminino. Em relação a faixa etária, nota-se que a maioria dos respondentes tem entre 18 a 28 anos (83,50\%). Enquanto 13,90\% tem entre 29 e 39 anos, e 2,60\% dos discentes da amostra tem acima de 40 anos. Foi evidenciado que a maior parte dos discentes são solteiros(as) $(68,80 \%)$, enquanto $28,70 \%$ são casados(as), $1,30 \%$ estão em união estável e 1,30\% divorciados(as).

\subsection{Análise Fatorial Exploratória do Construto Capacidade de Absorção Individual}

A análise fatorial exploratória teve o objetivo de verificar a unidimensionalidade e confiabilidade dos construtos, para em seguida, proceder com a regressão múltipla linear.

Conforme Carvalho, Ribeiro e Cintra (2015) a unidimensionalidade refere-se ao fato de os itens serem fortemente ligados entre si, resultando em um único conceito. O teste de unidimensionalidade tem o objetivo de que cada escala múltipla apresente itens com cargas elevadas em um único fator, ou seja, é o quanto a variável latente (variáveis observáveis que formam um conceito teórico) é representada pelas variáveis observáveis. Quanto a confiabilidade, é o grau de consistência entre as medidas de uma variável (HAIR JR. et al., 2009).

Foi elaborada a correlação existente entre as variáveis presentes nas dimensões que compõem o construto capacidade absortiva individual: aquisição (AQ), assimilação (AS), transformação (TR) e aplicação (AP). Além disso, também apresenta a comunalidade, o valor da medida de adequação da amostra (MSA), e também, as cargas alcançadas para cada indicador no fator único extraído dos dados.

De todos os itens relativos a dimensão aquisição, apenas o item AQ3 "Eu regularmente me aproximo de pessoas para adquirir novos conhecimentos, com o objetivo de aprimoramento pessoal e profissional" foi o único que não atingiu a comunalidade esperada de no mínimo 0,40 , os demais itens da variável aquisição tiverem valores satisfatórios. Em relação a medida de adequação da amostra (MSA) todos os itens que compõem a variável superam os valores sugeridos por Hair Jr. et al. (2009), acima de 0,50. Enquanto nas cargas fatoriais, os itens AQ1 "Eu regularmente recolho informações através de meios informais (por exemplo: conversas informais, grupos no whatsApp e redes sociais)", AQ2 "Eu regularmente observo o ambiente externo (mercado) para obter novas informações, conhecimentos ou tecnologias" e AQ3 não atingiram o valor mínimo de 0,60. Sendo assim, apenas os itens AQ4 "Eu regularmente pesquiso várias fontes de informações relevantes às atividades comuns no meu dia a dia" e AQ5

DOI: $10.14211 / x i-$ egepe-118150 
"Eu me mantenho constantemente atualizado com as últimas tecnologias ou conhecimentos relacionados a minha vida pessoal e profissional" foram selecionados para continuar na análise, pois eles possuem a comunalidade, a carga fatorial e MSA de acordo com as recomendações disponíveis na literatura.

Para a dimensão assimilação a variável possui correlação, todos os itens da variável assimilação atingiram valores adequados para a comunalidade. Quanto a MSA apenas o item AS5 "Eu frequentemente me encontro com colegas para trocar e analisar novos conhecimentos ou desenvolvimentos tecnológicos" não alcançou o valor mínimo de 0,50.

Em relação a carga fatorial os itens AS4 "Sou capaz de analisar e interpretar o impacto das novas demandas na minha vida pessoal e profissional" e AS5 não atingiram o valor desejado. Então, decidiu por usar apenas os itens AS1 "Sou rápido em reconhecer e compreender a utilidade de novos conhecimentos para meu dia a dia", AS2 "Eu compreendo rapidamente novas oportunidades para atender as necessidades da minha vida pessoal e profissional" e AS3 "Eu sei reconhecer e interpretar as mudanças em nosso mercado (por exemplo: concorrência, cliente e demanda)", pois estes se adequam perfeitamente aos padrões propostos pela literatura.

Quanto a dimensão transformação, todos os itens possuem valores de comunalidade superiores ao desejado. Quanto a MSA o item TR1 "Na minha área de atuação é comum eu armazenar o conhecimento recém adquirido para usar no futuro" não atingiu o valor mínimo de 0,50. Em relação as cargas no fator 1, os itens TR1 e TR4 "Eu considero regularmente as consequências das mudanças nas exigências do mercado" não alcançaram valores satisfatórios. Portanto, foi decido utilizar apenas os itens TR2 "Eu tenho a capacidade de conectar com o sucesso o meu conhecimento com novos conhecimentos ou novas ideias" e TR3 "- Eu comumente utilizo novos conhecimentos para gerar novas ideias para o meu dia a dia", pois possuem todos os critérios para representar a dimensão transformação.

Quanto a dimensão aplicação, os itens se correlacionam, os itens AP1 "Eu regularmente reconsidero meus processos de trabalho atuais (ou práticas) para adaptá-los em conformidade com o novo conhecimento ou tecnologias", AP2 "Eu tenho a capacidade de trabalhar de forma mais eficaz através da adoção de novos conhecimentos ou tecnologias", AP3 "No meu dia a dia, eu utilizo regularmente novos conhecimentos ou novas tecnologias para desenvolver novas formas de fazer as coisas", AP4 "No meu dia a dia, eu sou eficiente em transformar novos conhecimentos em melhores processos de trabalho" e AP5 "Eu regularmente considero a melhor forma de aplicar novos conhecimentos ou tecnologias no meu dia a dia" atingiram valores satisfatórios de comunalidade, MSA e carga no fator 1. Portanto, todos os itens continuam na análise, pois atendem as premissas determinadas pela literatura.

Em seguida, foram analisados os valores dos testes da medida de adequação da amostra KMO (Kaiser-Meier-Olkin) que destaca se a amostra é adequada para uso da AFE, devendo alcançar valores superiores a 0,50 e, esfericidade de Bartlett levando ao grau de liberdade e significância conforme a tabela 1.

Tabela 1 - Teste de adequação das escalas aquisição, assimilação, transformação e aplicação após exclusões

\begin{tabular}{|c|c|}
\hline Medida de KMO e Teste de Bartlett (Aquisição) & \\
\hline Medida de adequação da amostra de Kaiser-Meyer-Olkin & 0,518 \\
\hline Teste de Esfericidade $\quad$ Qui quadrado aproximado & 25,906 \\
\hline Grau de Liberdade & 1 \\
\hline Significância & 0,000 \\
\hline
\end{tabular}

DOI: $10.14211 / x i-$ egepe-118150 


\begin{tabular}{|c|c|}
\hline \multicolumn{2}{|l|}{ Medida de KMO e Teste de Bartlett (Assimilação) } \\
\hline Medida de adequação da amostra de Kaiser-Meyer-Olkin & 0,666 \\
\hline $\begin{array}{ll}\text { Teste de Esfericidade } & \text { Qui quadrado aproximado }\end{array}$ & 49,004 \\
\hline Grau de Liberdade & \\
\hline $\begin{array}{lc}\text { Significância } & 0,000\end{array}$ & \\
\hline \multicolumn{2}{|l|}{ Medida de KMO e Teste de Bartlett (Transformação) } \\
\hline Medida de adequação da amostra de Kaiser-Meyer-Olkin & 0,525 \\
\hline $\begin{array}{ll}\text { Teste de Esfericidade } & \text { Qui quadrado aproximado }\end{array}$ & 22,079 \\
\hline Grau de Liberdade & \\
\hline $\begin{array}{ll}\text { Significância } & 0,000 \\
\end{array}$ & \\
\hline \multicolumn{2}{|l|}{ Medida de KMO e Teste de Bartlett (Aplicação) } \\
\hline Medida de adequação da amostra de Kaiser-Meyer-Olkin & 0,766 \\
\hline Teste de Esfericidade $\quad$ Qui quadrado aproximado & 120,454 \\
\hline Grau de Liberdade & \\
\hline Significância & \\
\hline
\end{tabular}

Fonte: Dados da pesquisa (2019).

Os testes de esfericidade de Bartlett mostram uma significância de 0,000 em todos os indicadores da dimensão e a medida de adequação da amostra de Kaiser- Meyer-Olkin (KMO) alcançou valores de 0,518; 0,666; 0,525 e 0,766. Sendo assim, nenhuma variável obteve valores menores que 0,5. Após realização dos testes de KMO, esfericidade de Bartlett levando ao grau de liberdade e significância percebe-se que todos são considerados adequados devido a alcançarem os valores esperados para cada teste. Logo, atesta-se a fatorabilidade da matriz de correlação.

O processo de extração de fatores, que foi realizado por meio do método de componentes principais, com auxílio do software SPSS ${ }^{2} 23$, posteriormente a exclusão dos itens "AQ1, AQ2, AQ3", "AS4, AS5", "TR1, TR4", a fim de apresentar os fatores que contenham autovalor acima de $1(1,533 ; 1,944 ; 1,498 ; 2,820)$, consequentemente, valores de variância $(76,652 ; 64,804 ; 74,895 ; 56,397)$ acima do recomendado $(50 \%)$ por Hair Jr. et al. (2009). Concluindo a existência de consistência na medida para o construto (CARVALHO; RIBEIRO; CINTRA, 2015). Portanto, pode-se dizer que os discentes que participaram do Festival de Artes Empreendedoras possuem capacidade de absorção individual.

\subsubsection{Análise fatorial exploratória do construto intenção empreendedora}

A correlação existente entre as variáveis presentes nas dimensões que compõem o construto intenção empreendedora: intenção empreendedora (IE), normas subjetivas (NS), atitudes relativas ao comportamento (ARC) e controle do comportamento planejado (CCP). Além disso, também apresenta a comunalidade, o valor MSA e as cargas alcançadas para cada indicador no fator único extraído dos dados.

Após análise pode-se inferir que a variável possui correlação significativa. Na comunalidade, todos os itens atingiram os valores desejados de mínimo 0,40. No entanto, a MSA não é alcançada no item IE3 "Estou pronto para fazer qualquer coisa para ser um gestor de empresa". Quanto a carga no fator 1, os itens IE2 "Eu prefiro ser um gestor de uma empresa em vez de ser um funcionário em uma empresa" e IE3 não chegaram ao valor mínimo de 0,60. Optou-se pela utilização dos itens IE1 "Eu tenho muito pouco interesse em começar a gerir uma 
empresa" e IE4 "Vou concentrar todos os meus esforços para iniciar e executar meu próprio negócio".

A correlação da dimensão Atitude em relação ao comportamento nota-se que os itens possuem correlações significativas. A comunalidade de todos os indicadores atinge os valores sugeridos na literatura. Quanto a MSA, esta supera os valores recomendados de no mínimo 0,50 (HAIR JR. et al., 2009). Em relação a carga fatorial, os itens ARC1 "Se eu tivesse oportunidade e recursos, gostaria de abrir uma empresa para mim", ARC2 "Ser um empreendedor implicaria grande satisfação para mim" e ARC3 "Uma carreira como empresário é atraente para mim" atingem valores satisfatórios. Logo, nenhum indicador da dimensão é excluído.

Para as Normas subjetivas as variáveis possuem correlações significativas. A comunalidade alcança os valores esperados de mínimo 0,40. A MSA atinge os valores recomendados de no mínimo 0,50 (HAIR JR. et al, 2009). Quanto as cargas fatoriais, os itens NS1 "Os seus parentes", NS2 "Os seus amigos mais próximos", NS3 “Os seus colegas" e NS4 "Outras pessoas que são importantes para você" possuem valores adequados. Logo, optou-se pela utilização de todos os indicadores da dimensão.

Quanto ao Controle comportamental percebido os itens possuem correlação e alcançam os valores esperados na MSA, comunalidade e na carga fatorial. Portanto, os itens CCP1 "Iniciar a gestão de uma empresa e mantê-la funcionando seria fácil para mim", CCP2 "Estou preparado para iniciar um negócio viável", CCP3 "Eu posso controlar o processo de criação de uma nova empresa", CCP4 "Eu conheço os detalhes práticos necessários para criar uma nova empresa", CCP5 "Eu sei como desenvolver um projeto de criação de nova empresa" e CCP6 "Se eu tentasse criar uma nova empresa, teria uma alta probabilidade de sucesso" continuam na análise. Na tabela 2, são apresentados os valores de KMO (Kaiser-Meier-Olkin), esfericidade de Bartlett levando ao grau de liberdade e significância.

Tabela 2 - Teste de adequação das escalas intenção empreendedora, atitude em relação ao comportamento, normas subjetivas e controle comportamental percebido após exclusões

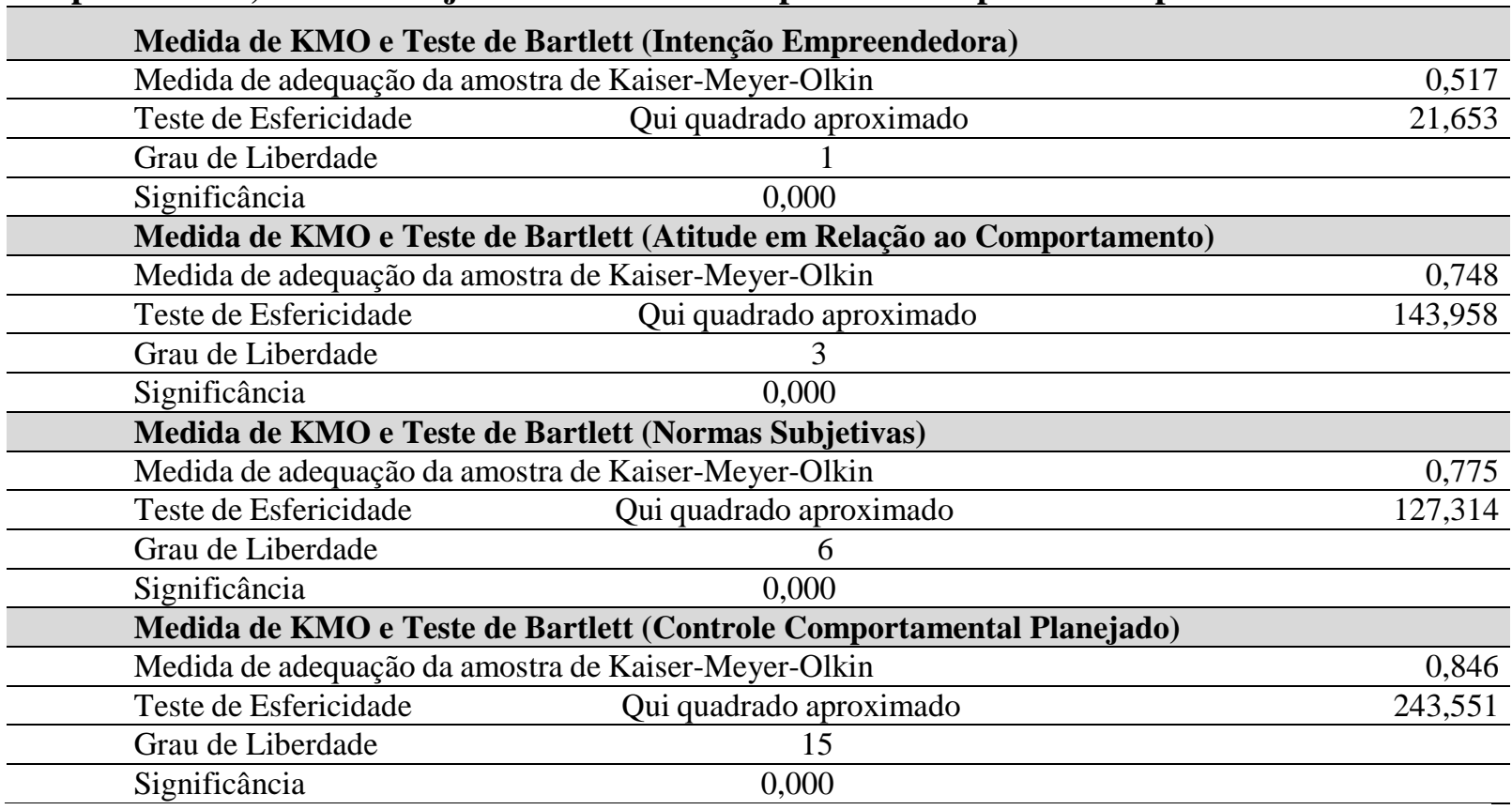

Fonte: Dados da pesquisa (2019). 
Os testes de esfericidade de Bartlett mostram uma significância de 0,000 em todos os indicadores da dimensão e a medida de adequação da amostra de Kaiser- Meyer-Olkin (KMO) alcançou valores de 0,$517 ; 0,748 ; 0,775$ e 0,846 . Sendo assim, nenhuma variável obteve valores menores que 0,5. Após realização dos testes de KMO, esfericidade de Bartlett levando ao grau de liberdade e significância percebe-se que todos são considerados adequados devido a alcançarem os valores esperados para cada teste. Logo, atesta-se a fatorabilidade da matriz de correlação.

O processo de extração de fatores, que foi realizado por meio do método de componentes principais, com auxílio do software SPSS ${ }^{2} 23$, posteriormente a exclusão dos itens "IE2, IE3", a fim de apresentar os fatores que contenham autovalor acima de $1(1,494$; $2,498 ; 2,707 ; 3,791)$, consequentemente, valores de variância $(74,686 ; 83,264 ; 67,666$; 63,186) acima do recomendado (50\%) por Hair Jr. et al. (2009). Concluindo a existência de consistência na medida para o construto (CARVALHO, RIBEIRO e CINTRA, 2015). Portanto, pode-se dizer que os discentes que participaram do Festival de Artes Empreendedoras possuem intenção empreendedora.

Em seguida, a fim de observar cada fator extraído e extrair os escores fatoriais, a AFE foi aplicada novamente em cada uma das dimensões dos construtos CAI e IE. Segundo Carvalho, Ribeiro e Cintra (2015), os escores fatoriais permitem que os valores da variável original sejam padronizados com o objetivo de que suas médias estejam no valor de zero e desvio padrão de 1 .

\section{Análise de Regressão Múltipla}

A partir dos escores fatoriais, buscou-se confirmar a relação existente entre as variáveis e se elas são relacionadas de forma linear, tornando possível a aplicação de regressão múltipla linear. A regressão múltipla linear possibilitou gerar as estatísticas dos resíduos e o diagnóstico de colinearidade. Quanto à normalidade dos dados, já havia sido realizada por meio da AFE, sendo assim, as estatísticas dos resíduos que consideram a média dos mesmos $(0,000)$ como sendo nulos os erros aleatórios. A média dos valores é nula e o valor do desvio padrão é 1 .

Tabela 3 - Estatísticas dos Resíduos da relação entre a Capacidade de Absorção Individual e Intenção Empreendedora

\begin{tabular}{c|l|l|l|l|l}
\hline & Mínimo & Máximo & Média & \multicolumn{1}{l|}{ Desvio Padrão } & N \\
\hline Valor predito &, 9471468 & 2,1237576 &, 0000000 &, 52572769 & 80 \\
\hline Resíduo & 1,90465581 & 1,88656843 &, 00000000 &, 85065292 & 80 \\
\hline Valor Predito Padrão & $-1,802$ & 4,040 &, 000 & 1,000 & 80 \\
\hline Resíduo Padrão & $-2,182$ & 2,161 &, 000 &, 974 & 80 \\
\hline
\end{tabular}

Fonte: Dados da pesquisa (2019). 


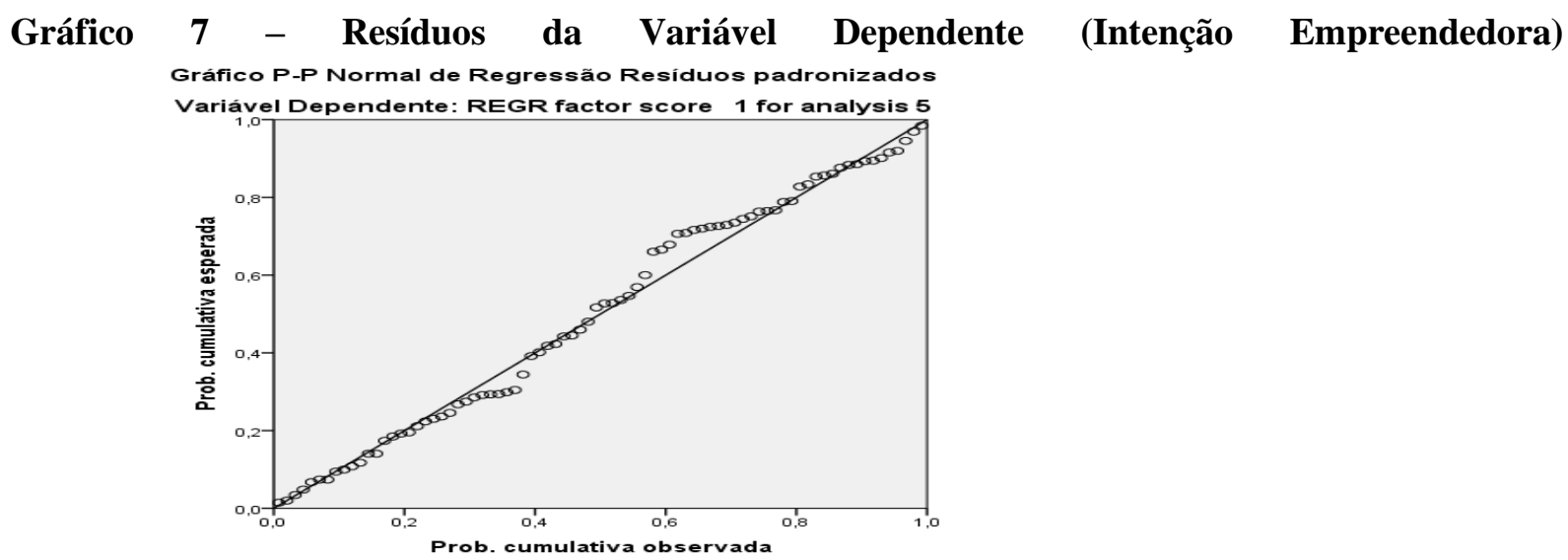

Fonte: Dados da pesquisa (2019).

De acordo com o gráfico acima, os resíduos da variável dependente estão próximos à reta principal com alguns desvios, no entanto, também ressalta que as variâncias podem ser consideradas homogêneas. O diagnóstico de colinearidade é apresentado na tabela 4.

Tabela 4 - Diagnóstico de colinearidade da Capacidade de Absorção Individual

\begin{tabular}{|c|c|c|c|c|c|c|c|}
\hline \multirow[b]{2}{*}{ Modelo } & \multirow[b]{2}{*}{ Autovalor } & \multirow[b]{2}{*}{$\begin{array}{l}\text { Índice } \\
\text { condição }\end{array}$} & \multicolumn{5}{|c|}{ Proporções de variância } \\
\hline & & & Constante & AQ & AS & TR & AP \\
\hline & 2,039 & 1,000 &, 00 &, 10 & 07 & , 10 &, 10 \\
\hline & 1,000 & 1,428 & 1,00 & 00 & , 00 & ,00 & 00 \\
\hline & 847 & 1,551 & ,00 &, 03 & 65 & 18 &, 10 \\
\hline & ,607 & 1,833 &, 00 &, 75 &, 19 & ,00 &, 30 \\
\hline & ,507 & 2,005 & 00 &, 12 & ,09 &, 72 &, 51 \\
\hline
\end{tabular}

Fonte: Dados da pesquisa (2019).

De acordo com a tabela acima, percebe-se que as variáveis independentes possuem relações lineares, no entanto, não podem ser consideradas perfeitas, pois as variâncias não estão alinhadas em uma reta.

Para analisar a hipótese da pesquisa (H1), foi realizada a regressão linear múltipla para observar a relação entre a Capacidade Absortiva Individual e a Intenção Empreendedora. Optou-se por realizar regressões lineares múltiplas para os modelos, a fim de avaliar cada variável do construto (variáveis independentes) em relação ao conjunto da intenção empreendedora que compõe a variável dependente. O quadro 3 apresenta as correlações entre os constructos.

Quadro 3 - Correlações Capacidade de Absorção Individual e Intenção Empreendedora

\begin{tabular}{|c|c|c|c|c|c|c|}
\hline & & IE & AQ & AS & TR & AP \\
\hline \multirow{5}{*}{$\begin{array}{l}\text { Correlação de } \\
\text { Pearson }\end{array}$} & IE & 1,000 &, 380 & ,277 & ,321 & ,460 \\
\hline & $\mathbf{A Q}$ & ,380 & 1,000 &, 350 & ,394 & ,367 \\
\hline & AS & ,277 &, 350 & 1,000 & ,204 & ,262 \\
\hline & TR & ,321 & ,394 & ,204 & 1,000 & ,477, \\
\hline & AP & ,460 & ,367 & ,262 & ,477 & 1,000 \\
\hline \multirow[t]{2}{*}{ Sig. (unilateral) } & IE & & ,000 & ,006 & ,002 &, 000 \\
\hline & $\mathbf{A Q}$ & ,000 & & ,001 & ,000 & ,000 \\
\hline
\end{tabular}


Fonte: Dados da pesquisa (2019).

\begin{tabular}{|l|l|l|l|l|l|} 
AS &, 006 &, 001 & &, 035 &, 009 \\
\hline TR &, 002 &, 000 &, 035 & &, 000 \\
\hline AP &, 000 &, 000 &, 009 &, 000 &
\end{tabular}

A partir do quadro acima, pode-se afirmar que os constructos possuem correlações entre si e apresentam valores de significância menores que 0,05. A tabela 4 aborda o sumário do modelo da correlação entre as variáveis da Capacidade Absortiva Individual e Intenção Empreendedora.

Tabela 4 - Sumário da Hipótese

\begin{tabular}{r|l|l|r|r|r}
\hline Modelo & $\mathbf{R}$ & $\mathbf{R}^{2}$ & $\mathbf{R}^{2}$ Ajustado & F & Sig. \\
\hline &, 526 &, 276 &, 238 & 7,162 &, 000 \\
\hline
\end{tabular}

Fonte: Dados da pesquisa (2019).

De acordo com a tabela acima, é possível confirmar a existência de uma relação positiva $\left(\mathrm{R}^{2}=0,276\right)$ entre as variáveis $\mathrm{AP}, \mathrm{AS}, \mathrm{TR}$ e AP (variáveis independentes) com a IE (variável dependente), pois $\mathrm{F}=7,162, \mathrm{P}<0,05$.

Quadro 5 - ANOVA

\begin{tabular}{|l|c|c|c|l|l|}
\hline Modelo & Soma dos Quadrados & Gl & Quadrado Médio & F & Sig. \\
\hline 1 Regressão & 21,835 & 4 & 5,459 & 7,162 &, 000 \\
Resíduo & 57,165 & 75 &, 762 & & \\
Total & 79,000 & 79 & & & \\
\hline
\end{tabular}

Fonte: Dados da pesquisa (2019).

A utilização da ANOVA teve o objetivo de confirmar a variável IE como dependente e as variáveis AP, AQ, TR e AS como preditoras. Diante disso, aceita-se H1.

H1 aceita: A capacidade de absorção individual tem influência positiva na intenção empreendedora.

De acordo com a literatura, a intenção empreendedora é formada pelas normas subjetivas, controle comportamental percebido e atitudes em relação ao comportamento, por isso foi realizada uma matriz de correlação comparando os escores fatoriais de cada dimensão com a IE, conforme a tabela 18 a seguir.

Tabela 18 - Correlação Variáveis Intenção Empreendedora versus Intenção Empreendedora

\begin{tabular}{c|c|c|c|c}
\hline & IE & ARC & NS & CCP \\
\hline IE & 1 &,- 646 &,- 331 &,- 431 \\
\hline Sig & &, 000 &, 003 &, 000 \\
\hline ARC &,- 646 & 1 &, 424 &, 331 \\
\hline Sig &, 000 & &, 000 &, 003 \\
\hline NS &,- 331 &, 424 & 1 &, 361 \\
\hline Sig &, 003 &, 000 & &, 001 \\
\hline CCP &,- 431 &, 331 &, 361 & 1 \\
\hline Sig &, 000 &, 003 &, 001 & \\
\hline
\end{tabular}

Fonte: Dados da pesquisa (2019).

Segundo a tabela acima, nota-se que a Intenção Empreendedora é influenciada pelas dimensões Atitudes Relativas ao Comportamento, Normas Subjetivas e Controle do Comportamento Planejado, pois as variáveis se correlacionam e possuem valores de

DOI: $10.14211 / x i-e g e p e-118150$ 
significância menores que 0,05. Essa informação corrobora com os resultados da Análise Fatorial Exploratória.

\section{CONSIDERAÇÕES FINAIS}

A pesquisa foi construída baseada no objetivo de analisar a influência da capacidade absortiva individual na intenção empreendedora dos discentes que participaram do Festival de Artes Empreendedoras. Para atender ao primeiro objetivo específico da pesquisa, foi utilizada a análise descritiva dos dados a fim de apresentar os aspectos socias dos respondentes. As análises univariada, fatorial exploratória, correlação e de regressão múltipla linear, foram utilizadas para atender aos requisitos dos demais objetivos.

Baseado nos resultados encontrados é possível afirmar que os discentes que participaram do Festival de Artes Empreendedoras possuem capacidade de absorção individual como também intenção empreendedora, além disso pode-se afirmar que a relação entre as teorias é condizente com a literatura, como por exemplo, o estudo de Silveira, Auozani e Nascimento (2017). A pesquisa ressalta que a capacidade absortiva individual possui relação significativa com a intenção empreendedora, e que a intenção empreendedora possui relação significativa com a capacidade absortiva individual. Mesmo que os valores da correlação não tenham sido elevados, eles possuem coerência. Assim, os resultados respondem a todos os objetivos da pesquisa.

\section{REFERÊNCIAS}

AJZEN, I. Attitudes, traits, and actions: Dispositional prediction of behavior in social psychology. Em L. Berkowitz (Ed.), Advances in Experimental Social Psychology (Vol. 20, pp. 1-63). San Diego, CA: Academic Press, 1991.

ANDRADE, H. S. Efeitos da capacidade de absorção individual na capacidade de inovação individual mediados pelo domínio de aprendizagem aplicado em redes varejistas no município de Foz do Iguaçu. São Paulo, 2017. Dissertação de Mestrado, Universidade Presbiteriana Mackenzie, São Paulo, 2017.

BIRD, B. Implementing Entrepreneurial Ideas: the case for intention. Academy of Management Review, v. 13, n. 3, p. 442-453, 1988.

CANTILlON, R. Essai Sur La Nature du Commerce em Général, 1755. Reeditado e traduzido por the royal economic society by frank cass and company ltda, London 1959.

CARVALHO, A.O.; RIBEIRO, I.; CINTRA, R. F. Métodos Quantitativos: um tutorial sobre uso das técnicas de análise fatorial exploratória, correlação e regressão linear. In: I CINGEN CONFERÊNCIA INTERNACIONAL EM GESTÃO DE NEGÓCIOS, 2015, Cascavel. CCSA... Cascavel, 2015.

CARVAlHO, P. M. R.; GONZÁLEZ, L. Modelo explicativo sobre a intenção empreendedora. Comportamento Organizacional e Gestão, VOL. 12, N. ${ }^{\circ}$ 1, 43-65, 2006.

CERVO, A; BERVIAN, P. A.; DA SILVA, R. Metodologia Científica. $6^{\text {a }}$ ed. São Paulo: Pretince Hall, 2006. p. 50-54.

CHELL, E. The entrepreneurial personality: a social construction. 2 ed. New York: Taylor \& Francis, 313 p, 2008.

CHIAVENATO, I. Empreendedorismo: dando asas ao espírito empreendedor: empreendedorismo e viabilidade de novas. 2.ed. rev. e atualizada. São Paulo: Saraiva 2007. 
COHEN, W. M; LEVINTHAL, D. A. Innovation and learning: the two faces of R\&D. The Economics Journal. Vol. 99, pp. 569-596, 1989.

COHEN, W. M.; LEVINTHAL, D. A. Absorptive Capacity: a new perspective on learning and innovation. Administrative Science Quarterly, v.1, n.35, p. 128-152, 1990.

COOLEY, L. Entrepreneurship training and the strengthening of entrepreneurial performance. Final report. Contract. Washington: EUA, 1990.

DUCHEK, S. Capturing absorptive capacity: a critical review and future prospects. Schmalenbach Business Review, v.65, p 312-329, 2013.

ESCOBAR, M. A. R. Relação das capacidades dinâmicas e orientação empreendedora com o desempenho em agências de viagens moderada pelo ambiente organizacional. Biguaçu, 2012. Tese de Doutorado, Universidade do Vale do Itajaí. Biguaçu, 2012.

FÁVERO, L. P.; BELFIORE, P.; SILVA, F. L.; CHAN, B. L. Análise de dados - Modelagem multivariada para tomada de decisões. Rio de Janeiro: Elsevier, 2009.

FLATTEN, T. C.; ENGELEN, A.; ZAHRA, S. A.; BRETTEL, M. A measure of absorptive capacity: development and validation. European Management Journal, v. 29, p.98-116, 2011. GIMENEZ, F. A. P.; FERREIRA, J. M.; RAMOS, S. C. Configuração empreendedora ou configurações empreendedoras? Indo um pouco além de Mintzberg. In: Encontro Anual da Associação Nacional de Pesquisa e Pós-Graduação em Administração, V. 32, 2008, Rio de Janeiro. Anais... Rio de Janeiro: Anpad, 2008.

GODOLPHIM, J. V. F. Relação da capacidade absortiva e orientação para o mercado no desempenho das microempresas do Corede Serra do Rio Grande do Sul. Caxias do Sul, 2013. Dissertação de Mestrado, Universidade de Caxias do Sul. Caxias do Sul, 2013.

HAIR Jr, J. F.; BLACK, W. C.; BABIN, B. J.; ANDERSON, R. E.; TATHAM, R. L. Análise multivariada de dados. 5ed., Porto Alegre: Bookman, 2009.

KIM, L. Crisis Construction and Organizational Learning: Capability Building in Catching-up at Hyundai Motor. Organization Science, v.9, p. 506-521, 1998.

KOE, W.; SA'ARI, J. R.; MAJID, I.A.; ISMAIL, K. Determinants of Entrepreneurial Intention Among Millennial Generation. Procedia - Social and Behavioral Sciences, v. 40, p. 197-208, 2012.

KOERICH, G. V.; CANCELliER, E. L. P. L.; TEZZA, R. Capacidade de absorção, turbulência ambiental e desempenho organizacional: um estudo em empresas varejistas catarinenses. RAM, Rev. Adm. Mackenzie, 16(3), Edição Especial, 238-267, São Paulo, 2015. LACERDA, A. C. R. Efeitos da capacidade de absorção do conhecimento individual no domínio de aprendizagem com base na Taxonomia de Bloom. São Paulo, 2017. Dissertação de Mestrado, Universidade Presbiteriana Mackenzie, São Paulo, 2017.

LICHTENTHALER, U.; LICHTENTHALER, E. A capability-based framework for open innovation: complementing absorptive capacity. Journal of Management Studies, v.8, n.46, 2009.

LIÑÁN, F.; CHEN, Y. Development and Cross-Cultural Application of a Specific Instrument to Measure Entrepreneurial Intentions. Entrepreneurship: Theory \& Practice, v.33, n.3, p.593-617, 2009.

MACHADO, R. E. Influência do capital intelectual na capacidade absortiva e na inovação. Porto Alegre, 2014. Tese de Doutorado, Universidade Federal do Rio Grande do Sul, Porto Alegre, 2014.

MALHOTRA, N. K. Pesquisa de Marketing: uma orientação aplicada. 6.ed. Porto Alegre: Bookman, 2012. 
MCCLELLAND, D.C. The achieving society. Princeton, New Jersey, 1961.

MORALES, S. A. Relação entre competências e tipos psicológicos Junguianos nos empreendedores. Florianópolis, 2004. Tese de Doutorado, Universidade Federal de Santa Catarina, Florianópolis, 2004.

MORIAnO, J. A.; PAlací, F. J.; MORAleS, J. F. The Psychosocial Profile of the University Entrepreneur. Psychometric theory. New York, NY: McGraw-Hill, 2007.

OLIVEIRA, R. O.; BELASTRIN, A. Cooperação universidade-empresa: um estudo do projeto UNISINOS - HT Micron para o desenvolvimento de capacidade absortiva na área de semicondutores. Universidade do Vale do Rio dos Sinos - UNISINOS. São Leopoldo, 2015.

PICOLI, F. R.; TAKAHASHI, A. Capacidade de absorção, aprendizagem organizacional e mecanismos de integração social. RAC, Rio de Janeiro, v. 20, n. 1, art. 1, pp. 1-20, 2016. reconceptualization. Academy of Management Review, v. 32, n. 3, p. 774-786, 2007. RICHARDSON, R. J. Pesquisa Social: métodos e técnicas. São Paulo: Atlas, 1999.

SAY, J. B. A Treatise on Political Economy: or the Production, Distribution and Consumption of Wealt. ed. Clement C. Biddle, trans. C. R. Prinsep from the 4 th ed. Of the French, Philadelphia: grigg e Elliot, 1855.

SELLTIZ, C.; WRIGHTSMANN, L. S.; COOK, W. Métodos de Pesquisa nas Relações Sociais. São Paulo: Herder, 1967.

SHAPERO, A.; SOKOL, L. The social dimension of entrepreneurship. In: Encyclopedia of Entrepreneurship. Englewood Cliffs, NJ: Prentice Hall Inc, 1982.

SHOOK, C. L.; PRIEM, R. L.; MCGEE, J. E. Venture Creation and the Enterprising individual: a review and synthesis. Journal of Management, v. 29, n. 3, p. 379-399, 2003.

SILVEIRA, A., AUOZANI, L. R. S., NASCIMENTO, S. D. A abordagem das Capacidades Dinâmicas se Revela na Produção Científica de Intenção Empreendedora? In: Simpósio Internacional de Gestão de Projetos, Inovação e Sustentabilidade, São Paulo. Anais. São Paulo: VI SINGEP, 2017.

SOUZA, R. S. Intenção empreendedora: validação de modelo em universidade federais de Mato Grosso do Sul. São Paulo, 2015. Tese de Doutorado, Universidade Nove de Julho, São Paulo, 2015.

THOMPSON, E. R. Individual Entrepreneurial Intent: construct clarification and development of an internationally reliable metric. Entrepreneurship Theory \& Practice, v. 33, n. 3, p. 669-694, 2009.

VALE, G. V.; WILWINSON, J.; AMÂNCIO, R. Empreendedorismo, inovação e redes: uma nova abordagem. ERA-eletrônica, 2008.

VERGA-JURADO, J., GUTIERREZ-GRACIA, A.; FERNANDEZ-DE-LUCIO, I. Analyzing the Determinants of Firm's Absorptive Capacity: beyond R\&D. R\&D Management., v. 38, p.392-405,2008.

WANG, W.; LIU, L.; FENG, Y.; TIENAN, W. Inovação com o uso de IS: capacidade de absorção individual como mediador. Gestão Industrial e Sistemas de Dados. Vol. 114 Issue: 8, pp.1110-1130, 2014.

WINTER, S. G. Understanding Dynamic Capabilities. Strategic Management Journal, v.24, p. 991-995, 2003.

ZAHRA, S.A.; GEORGE, G. Absorptive Capacity: A Review, Reconceptualization, and Extension. Academy of Management Review, v.27, n.2, p.185-203, 2002. 